\title{
SCIENTIFIC REPORTS

\section{OPEN The kinetics of inorganic phosphate excretion in the acidotic rabbit during intravenous phosphate loading: a pseudo-ruminant model}

\begin{abstract}
Patrick A. Walsh $\mathbb{1}^{1 *} \&$ Daniel J. O’Donovan ${ }^{2}$
The rabbit is a much-used experimental animal in renal tubule physiology studies. Although a monogastric mammal, the rabbit is a known hindgut fermenter. That ruminant species excrete inorganic phosphate (Pi) mainly through the digestive system while non-ruminants eliminate surplus phosphate primarily through the renal system are acknowledged facts. To understand phosphate homeostasis in the acidotic rabbit, anaesthetized animals were infused with hydrochloric acid, after which they underwent intravenous phosphate loading. Biofluids were collected during the infusion process for analysis. Plasma Pi increased $\left(7.9 \pm 1.7\right.$ mmoles. Litre $^{-1}(\mathrm{~N}=5)$ vs $2.2 \pm 0.4$ mmoles. Litre $^{-1}$ $(\mathrm{N}=10)$ pre-infusion, $(\mathrm{p}<0.001))$, while urinary phosphate excretion was also enhanced $(74.4 \pm 15.3$ from a control value of $4.7 \pm 3 \mu \mathrm{mol} \cdot \mathrm{min}^{-1}(\mathrm{~N}=9$ ), pre-infusion, $\mathrm{p}<0.001)$ ) over an 82.5 minute $\mathrm{Pi}$ loading period. However, the fractional excretion of $\mathrm{Pi}(\mathrm{FePi})$ only increased from $14.2 \pm 5.4 \%$ to a maximum of $61.7 \pm 19 \%(\mathrm{~N}=5)$ over the infusion period. Furthermore, the renal tubular maximum

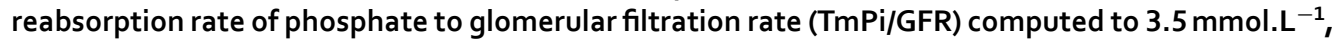
while a reading of $23.2 \mu \mathrm{mol} . \mathrm{min}^{-1} . \mathrm{Kg}^{0.75}$ was obtained for the transport maximum for Pi (TmPi). The high reabsorptivity of the rabbit nephrons coupled with possibly a high secretory capacity of the salivary glands for $\mathrm{Pi}$, may constitute a unique physiological mechanism that ensures the rabbit hindgut receives adequate phosphate to regulate caecal $\mathrm{pH}$ in favour of the resident metabolically - active microbiota. The handling of $\mathrm{Pi}$ by the rabbit is in keeping with the description of this animal as a monogastric, pseudo-ruminant herbivore.
\end{abstract}

The rabbit (Oryctolagus cuniculus) has an organ called the caecum that functions in a similar fashion to that of the rumen in a cow. However, unlike ruminants, this fermentation vessel in the rabbit is positioned not proximal to, but is located distal to the small intestine. The caecum in the rabbit has a capacity of about 10 times that of the stomach and about $40 \%$ of the total digestive tract ${ }^{1}$. A substantial portion of the rabbit's nutrient digestion takes place in the caecum through the activity of a diverse population of autochthonous microorganisms, known collectively as the microbiota ${ }^{2}$. Through the practice of caecotrophy, the rabbit is able to retrieve the micronutrient rich soft faeces at night, directly from the anus, and reingest it for processing and absorption of its content in the small intestine. The practice of caecotrophy is reported to contribute about $83 \%$ more niacin, $100 \%$ more riboflavin, $165 \%$ more pantothenic acid, $42 \%$ more cyanocobalamin (vitamin B12), and $100 \%$ more protein to the diet of a rabbit than is available without caecotrophy ${ }^{1,2}$. Because the rabbit does not regurgitate its food and chew the cud, but does rely on gut fermentation and caecotrophy for its nutritional wellbeing, this herbivorous species is sometimes referred to as a "pseudo-ruminant".

The daily intake of phosphorous by a rabbit depends on its diet. In the wild, the rabbit obtains much of its phosphorous from consuming Lucerne (Alfalfa) and available vegetables. The phosphorous is released from the phytates in the food through the action of microbial phytases in the rabbit's caecum. In the case of laboratory bred animals, the rabbits are provided with a pelleted diet that supplies, at a minimum, an amount of $1 \mathrm{~g}$ phosphorous per kilogram body weight as dicalcium phosphate ${ }^{3}$. In the case of commercial rabbit production units, the availability of phosphorous may be further enhanced by the addition of exogenous phytases to the formulated diet. 
After absorption in the gut, phosphorous is transported across cell membranes, as inorganic phosphate (Pi), by means of a secondary active transport process, wherein it exists as the main intracellular anion. $80-85 \%$ of total body phosphate is located within bone, while $\sim 15 \%$ is present within cells. Phosphate in plasma constitutes $<1 \%$ of the total body stores. At the physiological $\mathrm{pH}$ of 7.4 , phosphate exists in the plasma as a ratio of $\left[\mathrm{HPO}_{4}{ }^{2-}\right]$ : $\left[\mathrm{H}_{2} \mathrm{PO}_{4}^{-}\right] \sim 4: 1$. While most of the $\mathrm{Pi}$ in the plasma is free, approximately $10 \%$ is protein bound and $5 \%$ is complexed with sodium, calcium, and magnesium. $90-95 \%$ of the plasma phosphate is ultrafilterable at the glomerulus. Maintenance of the plasma concentration of $\mathrm{Pi}$ within a relatively narrow range is essential for a number of key cellular activities, including energy metabolism, signal transduction, bone formation, nerve signalling, muscle contraction, and as a constituent of nucleic acids, phospholipids, and milk in lactating animals. The buffering roles of phosphate in extracellular fluid, in the urine, and in the digestive system of ruminant species are well known.

The regulation of plasma phosphate levels is governed by a set of complex activities taking place in a series of feedback loops, involving the parathyroid gland - gut - bone - kidney axis ${ }^{4}$. In respect of the renal handling of phosphate, the TmPi/GFR has proven to be clinically a very useful index. TmPi/GFR measures maximum renal tubular phosphate reabsorption in mass per unit volume of glomerular filtrate. In adult humans, the $95 \%$ reference range is $0.8-1.35 \mathrm{mmol} . \mathrm{L}^{-15,6}$. Two main families of phosphate transporters facilitate the renal reabsorption of phosphate. These include the SLC34 family (NaPi-IIa \& NaPi-IIc) and the SLC20 family (PiT-1\& PiT-2), respectively ${ }^{7,8}$.

In addition to nutritional factors, a number of key regulators have been shown to play crucial roles in enabling the interplay between the organs regulating the plasma levels of phosphate. These include parathyroid hormone (PTH), calcitriol, and a number of phosphatonins, of which fibroblast growth factor- 23 and $\alpha$-klotho have been the best characterized. Klotho acts as a co-factor that is mandatory for FGF23 action ${ }^{7,8}$.

Phosphate loading studies have been carried out in a wide variety of species, including $\operatorname{man}^{9}, \operatorname{the} \operatorname{dog}^{10,11}$, rodents $^{12}$, the rabbit ${ }^{13-15}$, ovine $\mathrm{e}^{16}$, and bovine animals ${ }^{17}$, respectively. In the course of calibrating the stimulatory effect of intravenous isotonic sodium phosphate on urinary acid - base parameters in the acidotic rabbit, it became clear to $\mathrm{us}^{15}$ that the kinetics of phosphate excretion in this herbivore is notably dissimilar to that which is characteristically found in monogastric animals. In this paper, we demonstrate that in the acidotic, hyperphosphataemic rabbit, at least two mechanisms are active in regulating plasma phosphate concentration. These include the excretory role of the rabbit kidney along with an additional, equally effective system, involving possibly the salivary secretion of phosphate into the digestive tract.

\section{Methods}

Ethical approval. The study was carried out at the Physiology Laboratories of the National University of Ireland Galway (NUIG) in Ireland. The animal experiments were performed in accordance with Directive $2010 / 63 / \mathrm{EU}$, and ethics principles described by Grundy ${ }^{18}$. A permit to import the experimental animals from the United Kingdom was obtained from the Department of Agriculture (Veterinary Section), Kildare St., Dublin 2, Ireland. A license to undertake the animal experiments described in this paper, including ethical approval, was granted by the animal licensing committee at the Public Health Division of the Department of Health, Hawkins House, Dublin 2, Ireland.

Animal husbandry. Specific Pathogen Free (SPF) male New Zealand White (NZW) rabbits were used in the study. The animals were 3-6 months old, and weighed $3.28 \pm 0.54 \mathrm{Kg}$. The rabbits were obtained from a commercial supplier (Hylyne Rabbits Ltd, United Kingdom). They were housed individually in cages, in an environmentally controlled room $\left(20 \pm 1{ }^{\circ} \mathrm{C}, 35-60 \%\right.$ relative humidity, and 12:12 light-dark cycle). The animals were allowed free access to water and rabbit chow (Bio resources unit, Trinity College Dublin, Ireland).

Pre-operative preparation. On the day of the surgery, each animal (who had been fasted overnight) was pre-medicated with chlorpromazine hydrochloride (Largactil, Sanofi-Aventis: $2.5 \%, 25 \mathrm{mg} \mathrm{Kg}^{-1}$ ), followed 30-45 minutes later with intravenous pentobarbital (Nembutal, Abbot Laboratories: $5 \%, 15 \mathrm{mg} . \mathrm{Kg}^{-1}$ ) through a marginal ear vein. The anaesthetized rabbit was placed in dorsal recumbency, on a small operating table, and secured in position using four limb-restraining robes. Rectal temperature was maintained throughout the surgery at $39^{\circ} \mathrm{C}$, using a homoeothermic blanket system with a flexible measuring thermistor probe. The depth of anaesthesia was monitored closely during experimentation by way of cardiorespiratory measurements and checking for the absence of the palpebral and pedal reflexes, respectively.

A 12 FG de Pezzer urethral catheter was placed in the urinary bladder as described previously ${ }^{19}$, to facilitate the collection of timed urinary specimens during the induction of acidosis and afterwards during phosphate loading. Control urinary samples were collected from each animal over a 15 - minute period, immediately preceding the commencement of the intravenous phosphate loading process at zero time. At the end of the study, the animals were sacrificed by anaesthetic overdose.

Infusion of solutions. Infusions were made through the left jugular vein via an indwelling P.E. 50 cannula, which was connected to a loaded $60 \mathrm{ml}$ syringe, positioned on a Harvard I.V. syringe pump (model 2681). The animals were infused with isotonic saline for two hours before being rendered metabolically acidotic, as described in previous studies ${ }^{14,15}$. The hydrochloric acid infusion was replaced by isotonic saline for $30 \pm 5$ minutes, to allow a steady-state metabolic acidosis to become established, prior to the initiation of phosphate loading via the intravenous infusion of $0.1 \mathrm{M}$ sodium phosphate ( $\mathrm{pH} 7.4$ ) at $120 \mu \mathrm{mol} . \mathrm{min}^{-1}$.

Measurement of phosphate. Control blood and urinary samples were taken from each acidotic animal prior to the commencement of phosphate loading. Plasma \& urinary inorganic phosphate (Pi) concentrations were determined spectrophotometrically ${ }^{20}$. 
Data and statistical analysis. The data are presented as means $\pm \mathrm{SD}$, and statistical comparisons were performed using a Student's paired $t$ test, with statistical significance being taken as $P \leq 0.05$. Statistical analysis was made using GraphPad Prism version 8.0 for Windows, (GraphPad Software, La Jolla California USA, www. graphpad.com.)

\section{Results}

During the course of phosphate infusion, blood was sampled at the midpoint of each urinary collection period and harvested for plasma. Bioanalysis of the plasma samples showed that the phosphate concentration increased from a control value of $2.2 \pm 0.4 \mathrm{mmol}$.Litre ${ }^{-1}(\mathrm{~N}=10)$ to reach a maximum concentration of $7.9 \pm 1.7 \mathrm{mmol}$. Litre $^{-1}(\mathrm{~N}=5),(\mathrm{p}<0.001)$ at 82.5 minutes from the time of commencement of sodium phosphate infusion (Fig. 1). The increase occurred in three discernible phases. An early dose-dependent increase over the initial 20-25 minutes of the infusion process was followed by a period during which the rate of increase in plasma Pi began to reduce, after which an acute steady state was reached between 82.5 and 97.5 minutes, despite continuous infusion of sodium phosphate buffer solution, $\mathrm{pH}$ 7.4.

Urine was collected at 15-minute intervals during the course of inorganic phosphate loading of the acidotic rabbits. Even though isotonic sodium phosphate was being intravenously infused at a rate of $120 \mu \mathrm{mol}_{\mathrm{min}}^{-1}$, the maximum urinary phosphate excretion rate that was attained over the 82.5 minutes of phosphate loading was $62 \%$ lower at $74.4 \pm 15.3$ from a control value of $4.7 \pm 3.0 \mu$ mol. $\mathrm{min}^{-1}, \mathrm{~N}=9, \mathrm{p}<0.001$ ) (Fig. 2). Kinetic analysis of the plasma and urinary phosphate data showed that the urinary excretion of phosphate increased in a linear fashion above the TmPi/GFR value of $3.5 \mathrm{mmol}^{-1} \mathrm{~L}^{-1}$ (Fig. 3). This is very similar to what has been observed in such ruminants as the sheep ${ }^{21}$ and dairy $\operatorname{cow}^{17}$, but 3-4 fold greater than that found in $\operatorname{man}^{5}$.

Assuming a saturation kinetics model for phosphate reabsorption, a value of $16.3 \mathrm{ml} . \mathrm{min}^{-1}$ was calculated from the slope of the line for the glomerular filtration rate $\left(G_{F R}\right)$, equating to an average GFR of $5 \mathrm{ml} \cdot \mathrm{min}^{-1} \cdot \mathrm{kg}^{-1}$ for the group of rabbits under study (Fig. 3). Taking into consideration the extracellular fluid volume expansion that would have taken place following the infusion of isotonic fluids over the experimental period, the glomerular filtration data reported here compare favourably with the inulin measurements of GFR obtained in the conscious rabbit by Michigoshi et al. ${ }^{22}$.

An evaluation of the filtered loads of phosphate reaching the nephrons over the experimental period showed that an average transport maximum for inorganic phosphate (TmPi) of $56.7 \mu$ mol.min ${ }^{-1}$ or $23.2 \mu m . \mathrm{min}^{-1}$. Kg. ${ }^{0.75}$ was reached within 20 minutes from the time of commencement of the Pi loading process (Fig. 4). The TmPi value for the rabbit compares very well with that which has been reported for such ruminants as sheep and cattle, but very different to what is found in man, dog, or rodent ${ }^{21}$. The renal fractional excretion of phosphate $(\mathrm{FePi})$ increased from a control value of $14.2 \pm 5.4 \%(\mathrm{~N}=6)$ to reach a maximum of $61.7 \pm 19 \%(\mathrm{~N}=5)$ over the course of the infusion period. Furthermore, it is evident from the data (Table 1) that only after 80 minutes of phosphate loading did the rate of glomerular filtration of $\mathrm{Pi}$ approach the intravenous infusion rate of isotonic sodium phosphate.

The relatively low FePi profile (Table 1) coupled with a relatively constant plasma concentration of Pi, over the course of phosphate loading period, clearly provides evidence for the existence of an extrarenal pathway for Pi elimination in the experimental animals. This continuously active and very powerful inorganic phosphate scavenging mechanism alleviated the impact of both the parenterally administered and renal reabsorbed phosphate. Only in the last half of the phosphate-loading period, did renal elimination reach parity with the extrarenal route of phosphate disposal. We did not pursue to identify the nature of the extrarenal phosphate clearance mechanism(s), as it was outside the scope of the study at the time.

\section{Discussion}

The handling of phosphate has been studied extensively in monogastric animals and ruminants. In such monogastric species as man, rodents, and the dog, extracellular phosphate balance is regulated principally through renal phosphate excretion ${ }^{4,8,23}$. However, in the case of ruminants such as the cow, sheep, and goat, phosphate homeostasis is executed primarily within the digestive tract, through the mechanisms of salivary secretion and faecal excretion ${ }^{16,17,24}$. On route to undergoing disposal via faecal excretion in the ruminant, it is thought that phosphate fulfills an important buffering function in the rumen, where microbial fermentative processes produce enormous quantities of volatile short chain fatty acids.

The data analytics of our study on the acidotic, hyperphosphataemic rabbit, would indicate that phosphate homeostasis in this species is consistent with a ruminant model. Unlike other monogastric species, it is evident that in the rabbit, an extrarenal route of Pi elimination is the predominant mechanism by which excess inorganic phosphate is removed from this animal's body during the induced hyperphosphataemia. Analogous to other herbivores such as the sheep and goat, the rabbit may use its salivary glands as a phosphate-scavenging pathway to remove the toxic loads of phosphate from the blood plasma, which are ultimately excreted via the digestive tract. There may lie within the rabbit's salivary glands a PTH independent phosphate sensing mechanism that operates to regulate plasma phosphate levels. Supporting this hypothesis, is the observation by other investigators that in both intact, and thyroparathyroidectomised sheep, there exists a linear relationship between acutely induced changes in plasma phosphate concentration, and the phosphate level in parotid gland produced saliva ${ }^{16}$.

In the rabbit, there are four pairs of salivary glands. In order of size, they include the parotids, mandibular, sublingual, and zygomatic glands, respectively. Their anatomy ${ }^{1,25}$ and histology ${ }^{26,27}$ have been well described in the literature. The primary formation of saliva is known to take place in the terminal portions of the salivary glands, where each of the epithelial cells, takes up interstitial fluid formed by local blood capillaries, processes it, and secretes the formed fluid, containing water, electrolytes, and macromolecules, in a unidirectional manner, from the basolateral region to the apical lumen of each acinus. From the lumen, it passes through the ductal system 


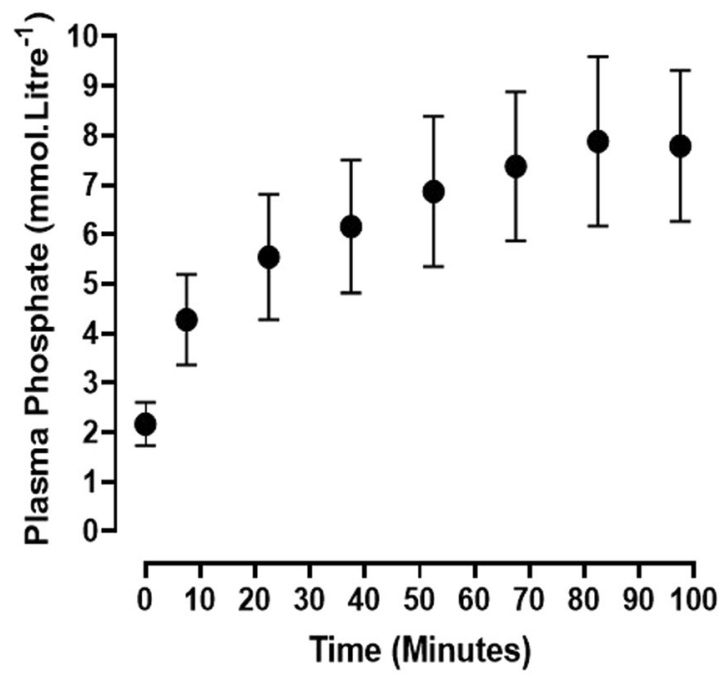

Figure 1. Plasma phosphate concentrations during the course of isotonic sodium phosphate ( $\mathrm{pH}$ 7.4) infusion at $120 \mu \mathrm{mol} . \mathrm{min}^{-1}$. The results are plotted as the Means \pm 1 S.D. $(\mathrm{N}=6)$.

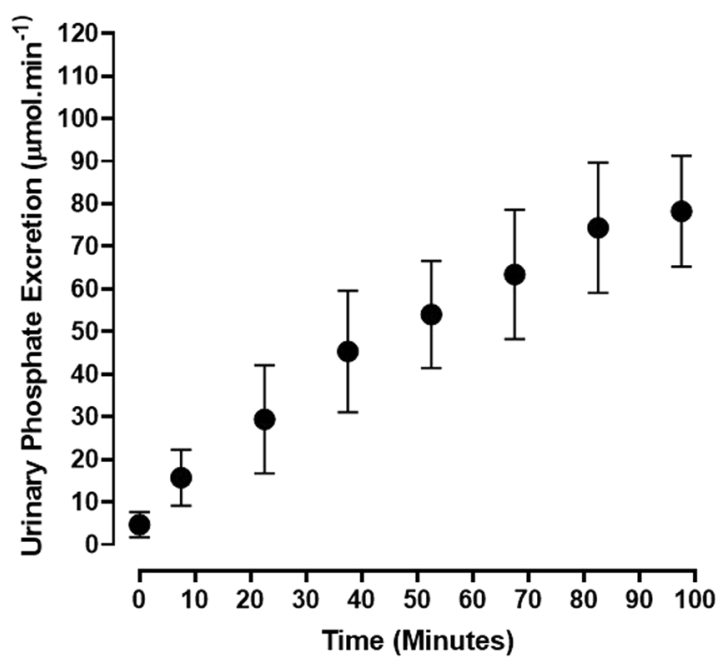

Figure 2. Urinary excretion rate of phosphate (Pi) during the course of phosphate infusion at $120 \mu \mathrm{mol}^{\mathrm{min}} \mathrm{m}^{-1}$. The results are presented as the Means \pm 1 S.D. $(\mathrm{N}=9)$.

where it may undergo further modification on its way to being secreted into the mouth. The transcellular events, which play key roles in the formation of saliva within the epithelial cells of the acini, have been studied extensively $^{28,29}$. In relation to phosphate, it has been shown that a Na ${ }^{+}$- coupled Pi transporter (NaPi-IIb (SLC34A2)), which utilizes the inwardly directed $\mathrm{Na}^{+}$gradient to concentrate $\mathrm{Pi}$ inside the cells, facilitates the uptake of phosphate by the basolateral membranes of the epithelial cells. Inorganic phosphate travels down its electrochemical gradient, exiting the cell through its apical membrane via an unidentified mechanism. It has been shown that this electrogenic Pi transporter has a concentrating capacity of 10,000. Concentrations of phosphate in the parotid saliva of sheep, for example, have been shown to reach the enormously high values of 20-40 $\mathrm{mmolar}^{28}$.

The ultimate fate of the salivary gland scavenged phosphate along the rabbit's lower digestive tract was not assessed in our studies for several reasons. Because the anaesthetized rabbits were in a dorsal recumbent position throughout the experiments, it would have been difficult to observe any changes in salivary flow. Secondly, the relatively short duration of the phosphate-loading period (1.75 hours) would not have allowed sufficient transit time for the salivary gland retrieved phosphate to arrive in the small intestine and caecum.

That the salivary glands are the extrarenal route of Pi elimination in the rabbit remains to be confirmed in future studies. Furthermore, it needs to be ascertained as to whether one or all four pairs of salivary glands have the capacity to secrete copious amounts of inorganic phosphate. It has been shown, for example, that the mandibular salivary glands in the rabbit secrete a continuous flow of saliva, while this role is fulfilled by the parotids in ruminants, and the sublingual glands in dogs and cats ${ }^{30}$. 


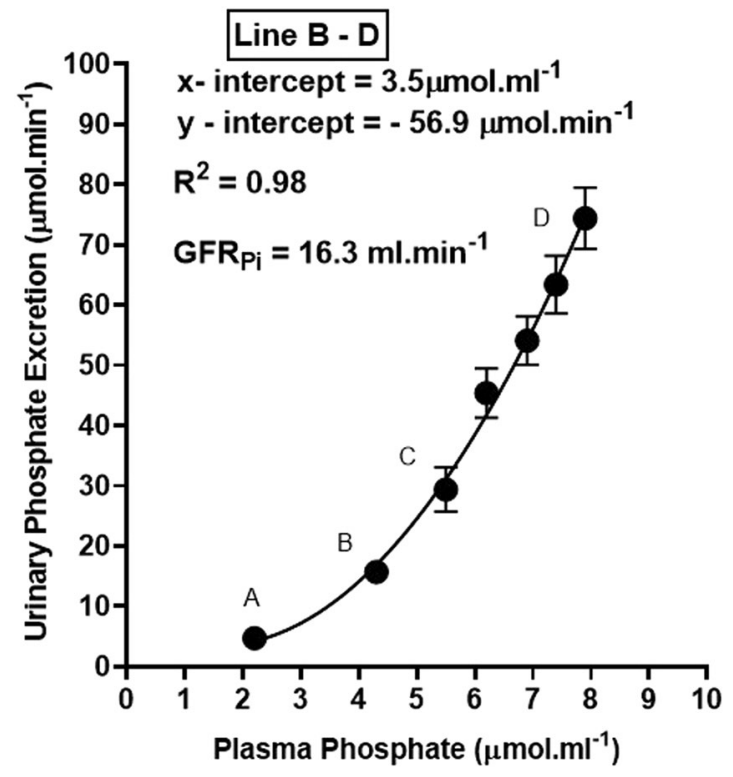

Figure 3. Plasma Pi concentration versus the urinary excretion rate of phosphate during the course of phosphate loading at $120 \mu \mathrm{mol} . \mathrm{min}^{-1}$. The values shown are the Means \pm SEM.

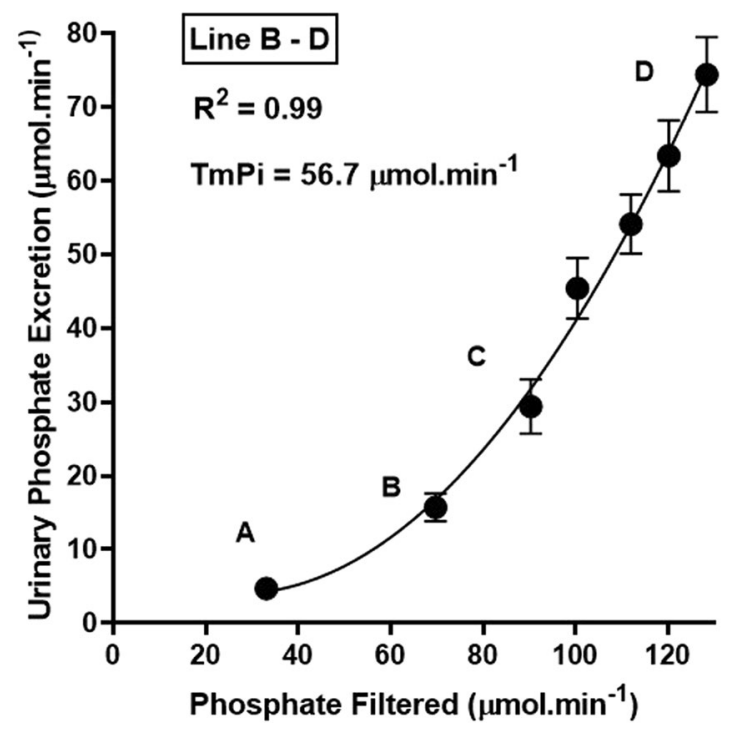

Figure 4. The rate of phosphate filtration versus the rate of urinary excretion of Pi during the course phosphate loading at $120 \mu \mathrm{mol} . \mathrm{min}^{-1}$. The values are shown as the Means \pm SEM.

\begin{tabular}{|l|l|l|l|l|}
\hline $\begin{array}{l}\text { Time } \\
(\text { Minutes })\end{array}$ & $\begin{array}{l}\text { Pi Filtered }(\boldsymbol{\mu m o l .} \\
\left.\text { min }^{-1}\right)\end{array}$ & $\begin{array}{l}\text { Pi Excreted }(\boldsymbol{\mu m o l} . \\
\left.\text { min }^{-1}\right)\end{array}$ & $\begin{array}{l}\text { Fraction Pi } \\
\text { Excreted FePi }(\%)\end{array}$ & $\begin{array}{l}\text { Pi Reabsorbed } \\
\left(\boldsymbol{\mu m o l . m i n} \mathbf{m i n}^{-1}\right.\end{array}$ \\
\hline 0 & $33.1 \pm 7.8(6)$ & $4.7 \pm 2.9(11)$ & $14.2 \pm 5.4(6)$ & $27.3 \pm 9.6(5)$ \\
\hline 7.5 & $69.7 \pm 15.0(6)$ & $15.7 \pm 6.6(12)$ & $22.5 \pm 10.8(6)$ & $50.4 \pm 15.5(6)$ \\
\hline 22.5 & $90.3 \pm 20.7(6)$ & $29.4 \pm 12.7(12)$ & $32.6 \pm 16.7(6)$ & $63.1 \pm 19.9(6)$ \\
\hline 37.5 & $100.4 \pm 21.9(6)$ & $45.4 \pm 14.3(12)$ & $45.2 \pm 18.1(6)$ & $51.5 \pm 32.1(6)$ \\
\hline 52.5 & $112 \pm 24.8(5)$ & $54.1 \pm 12.6(10)$ & $48.3 \pm 18.7(5)$ & $52.7 \pm 25.3(5)$ \\
\hline 67.5 & $120.2 \pm 24.5(5)$ & $63.4 \pm 15.2(10)$ & $52.8 \pm 19.9(5)$ & $52.2 \pm 23.9(5)$ \\
\hline 82.5 & $128.4 \pm 27.9(5)$ & $74.4 \pm 15.3(9)$ & $57.9 \pm 21.6(5)$ & $42.1 \pm 21.3(4)$ \\
\hline 97.5 & $127 \pm 24.9(5)$ & $78.3 \pm 13.0(7)$ & $61.7 \pm 19(5)$ & $36 \pm 27.9(2)$ \\
\hline
\end{tabular}

Table 1. Renal phosphate excretion kinetics in the acidotic rabbit during infusion of isotonic sodium phosphate (pH 7.4) at $120 \mu \mathrm{mol} . \mathrm{min}^{-1}$. A GFR $\mathrm{Pi}_{\mathrm{i}}$ of $16.3 \mathrm{ml} \cdot \mathrm{min}^{-1}$ was used to calculate the filtered Pi. The results are shown as the Means \pm S.D. 
Unlike humans, the dog, and rodent species, in which the kidney is the major site of phosphate excretion control, the rabbit kidneys play much more of a conservation role in withholding phosphate for extrarenal use. With very similar renal threshold (TmPi/GFR) and TmPi values to those found in sheep and cattle, it is clear that rabbit nephron reabsorptive kinetics for Pi resemble more those of ruminants than either of man, dog or rodent. Only in the last quarter of the phosphate loading process, when the filtered load of phosphate approached the rate of infusion of $\mathrm{Pi}$, did the renal fractional excretion of phosphate reach parity with the extrarenal route of Pi elimination. Furthermore, the high reabsorptive capacity of the rabbit nephrons for Pi reduces the animal's urinary titratable buffer capacity, and in so doing limits its ability to deal with an acidosis condition ${ }^{15}$.

Although three renal transporters (NaPi-IIa, NaPi-IIc, and PiT-2) have been identified, NaPi-IIa and NaPi-IIc account for the apical reabsorption of $80 \%$ of the filtered phosphate ${ }^{7}$. NaPi-IIa has been shown to be an electrogenic transporter (couples $3 \mathrm{Na}^{+}$to $1 \mathrm{Pi}$ ) and has a preference for $\mathrm{HPO}_{4}{ }^{2-}$, while NaPi-IIc is an electroneutral transporter, couples $2 \mathrm{Na}^{+}$to $1 \mathrm{Pi}$, and prefers the monovalent form of $\mathrm{Pi}\left(\mathrm{H}_{2} \mathrm{PO}_{4}^{-}\right)$as a substrate ${ }^{29}$. NaPi-IIa plays the most important role in the unidirectional and transcellular reabsorption of phosphate in the proximal tubules.

The abundance and activity of NaPi-IIa, and NaPi-IIc, transporters on the apical membranes of the proximal tubule cells is regulated by dietary $\mathrm{Pi}, \mathrm{PTH}, 1,25$ di-hyroxycholecalciferol, and FGF-23/klotho ${ }^{7}$. Hyperphosphataemia increases the secretion of PTH by the parathyroid glands and FGF23 by osteocytes, osteoblasts, and osteoclasts. The actions of PTH on the kidney occur within minutes, while the renal effects of FGF23 takes several hours to days ${ }^{31}$. While each of these two hormones cause down-regulation of the $\mathrm{Na}^{+}$Pi co-transporters ${ }^{32}$, FGF23 has also been shown to increase the expression of 24-hydroxylase, an enzyme that renders 1,25-dihydroxycholecalciferol $\left(1,25-(\mathrm{OH})_{2} \mathrm{D}_{3}\right)$ (calcitriol) inactive, further inhibiting phosphate reabsorption $^{33}$. Moreover, a low plasma level of calcitriol has also been shown to result in an increased salivary $\mathrm{Pi}$ concentration and secretion in ruminants ${ }^{34}$. The cumulative actions of PTH and FGF23 promote a phosphaturia. However, as in the hamster, the phosphaturic effect of PTH has been shown to be reduced in rabbit nephrons relative to the impact of this hormone on rodent renal tubules ${ }^{35,36}$.

In an evaluation of the impact of parenteral phosphate feeding on phosphate metabolism in the experimental rabbit, it is important to be aware that a number of factors, independent of the phosphate loading process, can influence the level of background phosphaturia in these animals. In the context of the study described in this paper, these would have included diet and respective blood acid-base status of the animals at the time of phosphate administration.

Previous investigators ${ }^{37}$ have established that the proportion of phosphate excreted in the urine can vary depending on the acid/alkali content of their diet. For example, rabbits fed carrots (alkaline diet) excreted $25 \%$ of the ingested phosphate in the urine, while those fed a mixed diet of carrots and oats showed a 50\% excretion as urinary phosphate, and finally those given oats exclusively (acidic diet) demonstrated a 100\% excretion as urinary phosphate. The rabbits in this study were fed a commercial pelleted diet, formulated to the dietary specifications of an herbivore, as described in the husbandry section.

With respect to blood acid base status, animal studies have revealed that metabolic acidosis can promote a phosphaturia by at least three independent mechanisms. The first involves an acidosis-mediated inhibition of the glycolytic rate ${ }^{38}$, decreasing the cellular uptake of phosphate. Secondly, to enhance urinary net acid excretion, increasing amounts of phosphate are absorbed from the intestine and released from bone into the bloodstream, leading to an amplification of the urinary titratable acid excretion ${ }^{39,40}$. Thirdly, studies have shown that while PiT1 \& PiT2 transporters are increased over 7 days during metabolic acidosis, there is a significant inhibition of NaPi-IIa transporter activity, leading to a decrease in the renal uptake of phosphate, further potentiating the phosphaturia. A modulation of the trafficking of the transporter protein to the apical cell membrane, the reduced availability of divalent $\mathrm{HPO}_{4}{ }^{2-}$ at urinary $\mathrm{pH} \leq 6.0$, and a decreased synthesis of $\mathrm{NaPi}$-IIa protein have been collectively shown to account for the inhibited $\mathrm{Na}^{+} / \mathrm{Pi}$ co-transporter activity observed in metabolic acidosis ${ }^{41}$. In complete contrast, it has been shown that metabolic acidosis increases $\mathrm{NaPi}$-IIb abundance in the ileum of the rat $^{42}$, the physiological purpose of which is to facilitate an increased reabsorption of phosphate to buffer the extracellular acid load, in addition to minimizing the excessive liberation of phosphate from bone. In respect of the acidotic, hyperhophataemic rabbits in this study, it would be interesting to ascertain if salivary gland NaPi-IIb is affected in a similar fashion.

Phosphate, calcium, and magnesium metabolism are very closely interconnected in many monogastric animals, as similar regulating hormones govern their activities. However, in the rabbit, whereas the digestive system appears to be the primary route for phosphate excretion, urine is the major route for calcium and magnesium excretion ${ }^{43,44}$. In contrast to the intestinal control of Pi uptake by $1,25-(\mathrm{OH})_{2} \mathrm{D}_{3}$, rabbit gut calcium absorption is independent of calcitriol regulation. Rather, a balance between dietary intake and urinary excretion determines the serum total calcium level in this species. Hence, a high intake of calcium is responsible for rabbit urine having a thick creamy appearance. High plasma citrate concentrations facilitate the urinary excretion of copious quantities of ultrafilterable calcium by this species ${ }^{1}$.

It is clear that future research studies are required to characterize the unique kinetic properties of the transporters responsible for phosphate reabsorption in the rabbit kidney, in addition to determining what hormonal and other factors might influence their respective activities during hyperphosphataemia. The extrarenal mechanisms of plasma phosphate regulation that appear to operate in the rabbit undoubtedly warrant further investigation. In this regard, the secretory role of the salivary glands in excreting inorganic phosphate into the digestive tract has to be investigated at the outset. The inter-relationship between the parathyroid and salivary glands in the homeostatic regulation of plasma phosphate levels in the rabbit requires a detailed appraisal, including identifying the location and biochemical nature of a plasma phosphate sensing mechanism. One might postulate that an avid reclamation and secretion of phosphate by the salivary glands, coupled with a ruminant-like kidney phosphate kinetics model, may make it possible for the rabbit caecum to harvest adequate amounts of inorganic phosphate to regulate the $\mathrm{pH}$ therein, and in so doing, prevent a transfaunation of the resident microbiota taking place ${ }^{45}$. The findings of this study confirm the description of the rabbit as a monogastric, pseudo-ruminant herbivore. 
Received: 23 October 2019; Accepted: 17 February 2020;

Published online: 04 March 2020

\section{References}

1. Brewer, N. R. Biology of the rabbit. Journal of the American Association for Laboratory Animal Science: JAALAS 45, 8-24 (2006).

2. Mi, L. et al. Comparative Analysis of the Microbiota Between Sheep Rumen and Rabbit Cecum Provides New Insight Into Their Differential Methane Production. Frontiers in Microbiology 9, 575, https://doi.org/10.3389/fmicb.2018.00575 (2018).

3. Nutrition of the rabbit. 2nd edn, 1-324 (CAB International, 2010).

4. Penido, M. G. \& Alon, U. S. Phosphate homeostasis and its role in bone health. Pediatric Nephrology (Berlin, Germany) 27, 2039-2048, https://doi.org/10.1007/s00467-012-2175-z (2012).

5. Payne, R. B. Renal tubular reabsorption of phosphate (TmP/GFR): indications and interpretation. Annals of Clinical Biochemistry 35(Pt 2), 201-206, https://doi.org/10.1177/000456329803500203 (1998).

6. Bijvoet, O. L. Relation of plasma phosphate concentration to renal tubular reabsorption of phosphate. Clinical Science 37, 23-36 (1969).

7. Jacquillet, G. \& Unwin, R. J. Physiological regulation of phosphate by vitamin D, parathyroid hormone (PTH) and phosphate (Pi). Pflügers Archiv - European Journal of Physiology 471, 83-98, https://doi.org/10.1007/s00424-018-2231-z (2019).

8. Manghat, P., Sodi, R. \& Swaminathan, R. Phosphate homeostasis and disorders. Annals of Clinical Biochemistry 51, 631-656, https:// doi.org/10.1177/0004563214521399 (2014).

9. Scanni, R., vonRotz, M., Jehle, S., Hulter, H. N. \& Krapf, R. The human response to acute enteral and parenteral phosphate loads. Journal of the American Society of Nephrology: JASN 25, 2730-2739, https://doi.org/10.1681/asn.2013101076 (2014).

10. Bank, N. The effect of buffer loading upon ammonium excretion in the dog. The Journal of Clinical Investigation 40, 573-578, https:// doi.org/10.1172/jci104285 (1961).

11. Hellman, D., Baird, H. R. \& Bartter, F. C. Relationship of maximal tubular phosphate reabsorption to filtration rate in the dog. The American Journal of Physiology 207, 89-96, https://doi.org/10.1152/ajplegacy.1964.207.1.89 (1964).

12. Thomas, L. et al. Acute Adaption to Oral or Intravenous Phosphate Requires Parathyroid Hormone. Journal of the American Society of Nephrology: JASN 28, 903-914, https://doi.org/10.1681/asn.2016010082 (2017).

13. Hashim, U., Dom, S. \& Hassan, H. Effects of Prolonged Intravenous Phosphate Administration On Rabbit's Serum Calcium. Research Updates in Medical Sciences (RUMeS) 3, 19-23 (2015).

14. Yu, H. L., Giammarco, R., Goldstein, M. B., Stinebaugh, D. J. \& Halperin, M. L. Stimulation of ammonia production and excretion in the rabbit by inorganic phosphate. Study of control mechanisms. The Journal of Clinical Investigation 58, 557-564, https://doi. org/10.1172/jci108501 (1976).

15. Walsh, P. A. \& O'Donovan, D. J. An appraisal of the in vivo role of phosphate as a modulator of urinary ammonium and titratable acid excretion in the acidotic rabbit. Journal of Animal Physiology and Animal Nutrition 103(5), 1571-1577, https://doi.org/10.1111/ jpn.13143 (2019).

16. Manas-Almendros, M., Ross, R. \& Care, A. D. Factors affecting the secretion of phosphate in parotid saliva in the sheep and goat. Quarterly Journal of Experimental Physiology (Cambridge, England) 67, 269-280 (1982).

17. Kasmaei, K. (ed Pet Feeding \& Care) $1-30$ (Swedish University of Agricultural Sciences (SLU), Sweden, 2010).

18. Grundy, D. Principles and standards for reporting animal experiments in The Journal of Physiology and Experimental Physiology. The Journal of Physiology 593, 2547-2549, https://doi.org/10.1113/jp270818 (2015).

19. Walsh, P. A. \& O'Donovan, D. J. Collection of untainted urinary specimens from the bladder of an anesthetized rabbit. Lab Animal 45, 112-114, https://doi.org/10.1038/laban.953 (2016).

20. Taussky, H. H. \& Shorr, E. A microcolorimetric method for the determination of inorganic phosphorus. The Journal of Biological Chemistry 202, 675-685 (1953).

21. Tomas, F. M. Renal response to intravenous phosphate infusion in the sheep. Australian Journal of Biological Sciences 28, 511-520 (1975).

22. Michigoshi, Y., Yamagishi, N., Satoh, H., Kato, M. \& Furuhama, K. Using a single blood sample and inulin to estimate glomerular filtration rate in rabbits. Journal of the American Association for Laboratory Animal Science: JAALAS 50, 702-707 (2011).

23. Prasad, N. \& Bhadauria, D. Renal phosphate handling: Physiology. Indian Journal of Endocrinology and Metabolism 17, 620-627, https://doi.org/10.4103/2230-8210.113752 (2013).

24. Shirazi-Beechey, S. P. et al. Mechanisms of phosphate transport in sheep intestine and parotid gland: response to variation in dietary phosphate supply. Experimental Physiology 76, 231-241 (1991).

25. Matosz, B., Dezdrobitu, C., Martonos, C., Luca, V. \& Damian, A. Scientific Works. Series C. Veterinary Medicine 63, 11-14 (2017).

26. Roa, I. \& Del Sol, M. Parotid Gland Comparative Microscopic Anatomy. Int. J. Morphol. 37, 701-705 (2019).

27. Al-Saffar, F. Histomorphological and histochemical study of the major salivary glands of adult local rabbits. International Journal of Advanced Research 11, 378-402 (2014).

28. Vayro, S., Kemp, R., Beechey, R. B. \& Shirazi-Beechey, S. Preparation and characterization of basolateral plasma-membrane vesicles from sheep parotid glands. Mechanisms of phosphate and D-glucose transport. The Biochemical Journal 279(Pt 3), 843-848, https:// doi.org/10.1042/bj2790843 (1991)

29. Virkki, L. V., Biber, J., Murer, H. \& Forster, I. C. Phosphate transporters: a tale of two solute carrier families. American Journal of Physiology. Renal physiology 293, F643-654, https://doi.org/10.1152/ajprenal.00228.2007 (2007).

30. The Biology of the Laboratory Rabbit. 2nd edn, (Academic Press, 1994).

31. Bacic, D. et al. The renal $\mathrm{Na}+$ /phosphate cotransporter $\mathrm{NaPi}-\mathrm{II}$ is internalized via the receptor-mediated endocytic route in response to parathyroid hormone. Kidney International 69, 495-503, https://doi.org/10.1038/sj.ki.5000148 (2006).

32. Shaker, J. L. \& Deftos, L. In Endotext (eds K. R. Feingold et al.) (MDText.com, Inc., 2000).

33. Blaine, J., Chonchol, M. \& Levi, M. Renal control of calcium, phosphate, and magnesium homeostasis. Clinical Journal of the American Society of Nephrology: CJASN 10, 1257-1272, https://doi.org/10.2215/cjn.09750913 (2015).

34. Riad, F., Lefaivre, J. \& Barlet, J. P. 1,25-Dihydroxycholecalciferol regulates salivary phosphate secretion in cattle. The Journal of Endocrinology 112, 427-430, https://doi.org/10.1677/joe.0.1120427 (1987).

35. Dennis, V. W., Bello-Reuss, E. \& Robinson, R. R. Response of phosphate transport to parathyroid hormone in segments of rabbit nephron. The American Journal of Physiology 233, F29-38, https://doi.org/10.1152/ajprenal.1977.233.1.F29 (1977).

36. Dennis, V. W. Actions of parathyroid hormone on isolated renal tubules. Annals of the New York Academy of Sciences 372, 552-557, https://doi.org/10.1111/j.1749-6632.1981.tb15505.x (1981).

37. Underhill, F. \& Bogert, L. Urinary excretion of phosphates in the rabbit. J. Biol. Chem. 36, 521-530 (1918).

38. Relman, A. S. Metabolic consequences of acid-base disorders. Kidney International 1, 347-359, https://doi.org/10.1038/ki.1972.46 (1972).

39. Hulter, H. N. Hypophosphaturia impairs the renal defense against metabolic acidosis. Kidney International 26, 302-307, https://doi. org/10.1038/ki.1984.173 (1984).

40. Krapf, R., Glatz, M. \& Hulter, H. N. Neutral phosphate administration generates and maintains renal metabolic alkalosis and hyperparathyroidism. The American Journal of Physiology 268, F802-807, https://doi.org/10.1152/ajprenal.1995.268.5.F802 (1995). 
41. Ambuhl, P. M., Zajicek, H. K., Wang, H., Puttaparthi, K. \& Levi, M. Regulation of renal phosphate transport by acute and chronic metabolic acidosis in the rat. Kidney International 53, 1288-1298, https://doi.org/10.1046/j.1523-1755.1998.00901.x (1998).

42. Stauber, A. et al. Regulation of intestinal phosphate transport. II. Metabolic acidosis stimulates $\mathrm{Na}(+)$-dependent phosphate absorption and expression of the $\mathrm{Na}(+)-\mathrm{P}(\mathrm{i})$ cotransporter $\mathrm{NaPi}-\mathrm{IIb}$ in small intestine. American Journal of Physiology. Gastrointestinal and Liver Physiology 288, G501-506, https://doi.org/10.1152/ajpgi.00168.2004 (2005).

43. Kennedy, A. The urinary excretion of calcium by normal rabbits. Journal of Comparative Pathology 75, 69-74, https://doi. org/10.1016/0021-9975(65)90049-6 (1965).

44. Shareghi, G. R. \& Agus, Z. S. Magnesium transport in the cortical thick ascending limb of Henle's loop of the rabbit. The Journal of Clinical Investigation 69, 759-769, https://doi.org/10.1172/jci110514 (1982).

45. Lelkes, L. \& Chang, C. L. Microbial dysbiosis in rabbit mucoid enteropathy. Laboratory Animal Science 37, 757-764 (1987).

\section{Acknowledgements}

The authors gratefully acknowledge the financial support received for this research from the Medical Research Council of Ireland, the Department of Education, and the National University of Ireland Galway (Postgraduate Fellowship). We would like to thank Dr. Bindhu Nair for helping with the compiling of the references.

\section{Author contributions}

P.A.W. conceived the study, performed the experiments, evaluated the data, and wrote the manuscript. D.J.O'D. evaluated the data and assisted with the writing of the manuscript. Both authors agreed to the final manuscript.

\section{Competing interests}

The authors declare no competing interests.

\section{Additional information}

Correspondence and requests for materials should be addressed to P.A.W.

Reprints and permissions information is available at www.nature.com/reprints.

Publisher's note Springer Nature remains neutral with regard to jurisdictional claims in published maps and institutional affiliations.

(c) Open Access This article is licensed under a Creative Commons Attribution 4.0 International License, which permits use, sharing, adaptation, distribution and reproduction in any medium or format, as long as you give appropriate credit to the original author(s) and the source, provide a link to the Creative Commons license, and indicate if changes were made. The images or other third party material in this article are included in the article's Creative Commons license, unless indicated otherwise in a credit line to the material. If material is not included in the article's Creative Commons license and your intended use is not permitted by statutory regulation or exceeds the permitted use, you will need to obtain permission directly from the copyright holder. To view a copy of this license, visit http://creativecommons.org/licenses/by/4.0/.

(C) The Author(s) 2020 